\section{'I enjoy making people happy, and providing great care and treatment. It's fantastic to see my patients' smiles improve with treatment.'}

skated since a child'. She was called Rebecca... the one and only same Rebecca I had known as a dental officer in the community service and am now married to!

I currently work at three different private orthodontic practices, six days a week: Metamorphosis, a specialist practice in West London, and two multidisciplinary private practices, Portner Pittack Dental Practice in Mill Hill East and Orthodontics at 152 on Harley Street. So each day is a different journey to work. On the days I travel to Metamorphosis (about 1 hour 40 mins each way by car/tube), breakfast has to be at Le Pain Quotidien in Parsons Green - their toasted walnut or raisin bread with preserves is amazing. On other days I usually have shredded wheat and muesli at home.

I was attracted by orthodontics at the age of 11 . I would go to my dentist for check ups and I was taken with a glass cabinet full of colourful removable orthodontic appliances. Being inquisitive, I began to attend the dentist when the orthodontist treated patients and therein started my fascination of orthodontics. No one in the family had been to university nor was there a history of medicine and dentistry in the family. I am proud to now be in a very privileged position treating patients. I enjoy making people happy, and providing great care and treatment. It's fantastic to see my patients' smiles improve with treatment.

My day is usually a mixture of treating patients, joint clinics with orthodontic co-workers, and interdisciplinary clinics including restorative, oral surgery and periodontics colleagues. Each day is very different - a different part of London, starting and finishing at different times and treating very different groups of patients - it makes it very interesting.

I'm late home depending on which practice I have been working at, anytime from 7 to 9:30 pm. More often than not I'm in bed by $11 \mathrm{pm}$. I am an early bird and Rebecca is a night owl! In our spare time, we love to meet up with friends, get to the theatre and of course, there's ice skating.

In the last 12 months my career changed amazingly! I have been given a new lease of orthodontic and professional life which has opened my eyes to what is out there in the orthodontic world. I was head hunted, something which I had not heard of happening in the dental field, for a state of the art, private orthodontic practice, Metamorphosis. Having gone through many negotiations and interviews over a six-month period, I was given a fantastic opportunity to become clinical director at this entrepreneurial orthodontic practice. Though previously I've been non-risk-taking and conservative in nature, this was a fantastic opportunity and I have totally embraced the idea, opportunities given and challenges. I cannot wait!

INTERVIEW BY RUTH DOHERTY

\title{
AROUND THE WORLD
}

To mark World Oral Health Day (20th March 2015) people from around the globe gathered together to celebrate oral health. Here are some of the global events which took place this year to raise awareness about the importance of lifelong oral health.

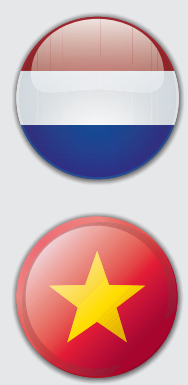

Over 300 students gathered in Amsterdam for the second edition of 'Toothcamp', an event which seeks to bring the world of dentistry closer to children. The participants were able to try out dentistry tools, learn the benefits of eating healthily and draw inspirational oral health messages on huge teeth.

The Department of Health of Hong Kong organised an Oral Health Carnival which attracted an audience of about 2,300 local citizens. Through interactive games, exhibitions on oral health information and teeth cleaning skills demonstrations in this Carnival, the public were reminded to take care of their oral health at an early age by adopting good oral self-care habits and seeking regular professional oral care.

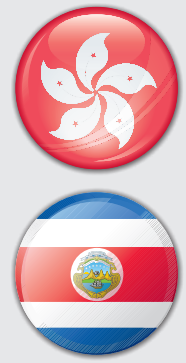

In Vietnam, over 6,000 people participated in the Run for Life WOHD 2015 race, which was also sponsored by the Vietnamese Dental Association (VOSA), Unilever and the Vietnamese Ministry of Health.

The second edition of the 'Lavatón' was organised in Costa Rica. This event consists of thousands of students in schools across the country brushing their teeth at the same time. It allowed the local dental association (Colegio de Cirujanos Dentistas de Costa Rica) to highlight the importance of oral health to children around the country.

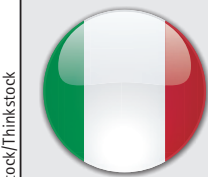
In Italy, dental students organised oral hygiene workshops for children in different schools and hospitals, carried out oral healthcare in centres for people with disabilities and even organised a student flashmob to highlight the importance of oral health.

\section{XYLITOL BENEFITS STILL UNPROVEN}

New research concludes that there is limited evidence to show that natural sweetener xylitol is effective in preventing dental cavities in children and adults.

According to evidence published in the Cochrane Library ${ }^{1}$ there is little high quality evidence that it is beneficial in the fight against tooth decay, which affects up to $90 \%$ of children and most adults worldwide.

Based on information from 4,216 school children who took part in two Costa Rican studies, they found low quality evidence that levels of tooth decay were 13\% lower in those who used a fluoride toothpaste containing xylitol for three years, compared to those who used a fluoride-only toothpaste. For other xylitol-containing products, such as xylitol syrup, lozenges and tablets, there was little or no evidence of any benefit.

Xylitol is a popular sugar substitute in sweets and it is already known to cause less damage to teeth than sugar. It has also been suggested that the addition of xylitol to products may help to prevent tooth decay by stopping the growth of decay-producing bacteria.

\footnotetext{
Riley P, Moore D, Ahmed F, Sharif M O Worthington $\mathrm{H} \mathrm{V}$. Xylitol-containing products for preventing dental caries in children and adults. Cochrane Database Syst Rev 2015; 3: CD010743.
} 